\title{
Breve confrontación do galego co inglés: achegas históricas e fonéticas
}

\author{
Xoán Vila Penedo \\ IESP Ánxel Casal (A Coruña) \\ xoanvila@edu.xunta.es
}

\begin{abstract}
Resumo:
O inglés, que pasa por ser a lingua franca internacional na actualidade, padeceu na Idade Media unha relación de sometemento a respecto do francés, como acontece na actualidade na Galiza entre o galego e o español; outrosí, o seu sistema fonético e fonolóxico presenta notorias diferenzas (mais tamén algunha relativa similutude) co noso idioma. E pensamos que ambos os aspectos, o histórico e o fonético, poden ser aproveitados nas salas de ensino, co que, na nosa opinión, o alumnado resultaría beneficiado.
\end{abstract}

\section{Palabras chave:}

historia do inglés, fonética inglesa, historia do galego, fonética galega.

\begin{abstract}
:
English, which is recognised as the world's most widely used, most important language and the international lingua franca, was subordinated to French across the Middle Ages, just the same as it happens in Galicia today between Galician and Spanish. In the same way its phonetic and phonological system shows great differences and also some similarities with our language. We consider that both, the phonetic and the historical aspect, could be developed and used in the classrooms so that the students would profit from that.
\end{abstract}

Key words:

History of the English Language, English Phonetics, History of the Galician Language, Galician Phonetics.

\section{Introdución}

Como profesor de inglés no ensino secundario en todos os seus niveis en diversos institutos, veño apreciando a necesidade de incrementar o uso e mellora da nosa lingua como idioma vehicular para estabelecer unha referencia comparativa coa lingua que ensino. Existe o prexuízo de que a Lingua Galega só se pode usar naquelas materias indicadas no Decreto de Normalización Lingüística e iso non ten por que ser así, xa que é tan válida e útil como calquera outra, para alén de prestixiar e reforzar nos usuarios e receptores a estima pola súa cultura. Felizmente, hoxe en día as editoras, mesmo as británicas, xa son conscientes desta inquedanza que sente 
un sector importante do alumnado e do profesorado e comezan a complementar os seus glosarios e resumos gramaticais non só en español, mais tamén en galego.

Fundamentalmente, a idea sería a de achegarmos o alumnado á aprendizaxe do inglés a través da súa propia realidade lingüística e isto é moi importante para a súa formación integral como persoas e para a súa incorporación futura ao mundo laboral. Todos os ensinantes galegos que estamos a impartir inglés coñecemos a dificultade que existe para explicar temas como o Present Perfect, por exemplo, formación verbal que non ten en galego un equivalente, e, por outra parte, verificamos tamén a facilidade con que o estudantado pronuncia o $\langle s h>$ equivalente ao $\langle x>$ galego.

Desde esta perspectiva, deberiamos prestar atención aos aspectos diferenciais que ofrecesen maiores dificultades e para iso cómpre manexarmos uns coñecementos básicos comparativos sobre disciplinas tales como, por exemplo, a fonética ou o léxico. O nivel de coñecemento básico deste último está fixado nun estudo realizado polo Consello de Europa (The Threshold level for modern language learning in schools, J. A. van Ek) que estabelece un mínimo necesario de palabras para se comunicar nunha lingua e que, no caso do inglés, sería de arredor das mil quiñentas.

Doutro lado, a utilidade cada vez maior das novas tecnoloxías nos centros de ensino fai necesario facermos as nosas aulas máis abertas ás outras culturas europeas, en especial ás que máis preto están de nós, como a portuguesa, a británica ou a española. Isto animaría os estudantes a veren estas linguas non só como materias académicas, mais como algo máis útil para daren e recibiren información sobre o mundo real. Todo este formulamento conduce directamente a unha fase posterior, en que todas aquelas persoas que maduraren e progresaren adecuadamente no coñecemento plurilingüístico terán moitas máis posibilidades nun futuro profesional non só na Galiza, mais tamén en todos os países en que se falan eses idiomas.

\section{Semellanzas e diferenzas entre o galego e o inglés. Condicións sociolingüísticas}

Como é sabido, o galego ten a súa orixe na Gallaecia romana, un territorio que abranxía a Galiza actual, o norte de Portugal e as comunidades limítrofes de Asturias, León e Zamora, rexións en que aínda se fala, prolongándose cara ao sur pola faixa atlántica. Ao ficar subordinado ao castelán no seu territorio de orixe, foi a variante portuguesa a que acadou expansión pola América, África e Asia. Esta avantaxe de pertencer a un dos sistemas lingüísticos máis utilizados do mundo tamén ten, en contrapartida, a desavantaxe de se ver oculto polo portugués, tan próximo na xeografía mais tan afastado no aspecto sociolóxico ou no político. Dado o 
percurso histórico do galego, de que o portugués constitúe a súa prolongación natural, coidamos que esta lingua e a súa realidade cultural deberían compartillarse como máis unha variante da diversidade galaico-portuguesa, así como acontece coas diversidades culturais e lingüísticas do Estado español.

Os celtas son o primeiro pobo de que hai rexistro nas Illas Británicas e na Galiza ${ }^{1}$, aínda que, no caso galego, non teñamos moitos restos da súa lingua nin das anteriores a ela, debido á influencia posterior dunha lingua tan desenvolvida como era o latín. No caso do inglés, o latín non logrou sobrevivir ás invasións posteriores de pobos xermánicos, cousa que si conseguiron as linguas dos celtas, aínda que noutras partes da Gran Bretaña ou do continente (a Escocia, Gales, a Irlanda, Illa de Mann, sudoeste de Inglaterra, a Cornualla e a Bretaña francesa). Os romanos estiveron en ambos os territorios, na Inglaterra e na Galiza, durante varios séculos, aínda que o resultado, debido ás diferenzas e ao tipo de colonización, á distinta construción de infraestruturas ou vías de comunicación, ás clases de asentamentos, aos motivos da conquista etc., foi ben distinto.

Após a romanización do territorio galaico, os suevos, pobo xermánico que ocupou a antiga Gallaecia (séculos V-VI), acabaron falando o latín, aínda que este adquiriu unhas peculiaridades propias. Para o caso do inglés, as tribos xermánicas, isto é, os anglos (procedentes da moderna Dinamarca), os saxóns (provenientes da actual Alemaña) e os xutos (chegados da Xutlandia) foron as que conformaron fundamentalmente a lingua, tamén chamada na época Lingua Anglorum. Neste sentido, Baugh / Cable (2002: 51) afirman que "the english language of today is the language that has resulted from the history of the dialects spoken by the Germanic tribes who came to England". E acrecentan que "it is impossible to say how much the speech of the Angles differed from that of the Saxons or that of the Jutes".

Canto aos celtas, foron asimilados polos romanos na Galiza, ao paso que na Gran Bretaña foron desprazados cara ao oeste polos pobos xermánicos, chamándolles wealas ('estranxeiros'), de onde provén o xentílico de orixe exoétnica welsh ('galés', 'galesa'); pola súa parte, os celtas chamábanlles saxóns aos seus conquistadores "indiscriminalety" (Baugh / Cable 2002: 50), mais os nomes angli e Anglia pouco a pouco acabaron designando a xente e o país, a través mesmo dos propios anglos, que se autodenominaban, en inglés antigo, angelcynn (Hogg 2002: 4), isto é, angel-kinn, "a raza dos anglos".

O vocabulario do inglés antigo (450-1150) é teutónico², aínda que moitas destas palabras desapareceron despois da conquista normanda (1066), cando o francés

\footnotetext{
1 A respecto do mundo dos celtas no contexto europeo, continúan a ser útiles na actualidade os xa clásicos traballos de Hubert (1988) ou Powell (2000).

2 Canto ao vocabulario do inglés antigo, véxase Hogg (2002: 102-114).
} 
ficou estabelecido como a lingua das clases altas, até se poder falar, conforme Millward (1996: 142), dunha época caracterizada polo declive do inglés ("English in decline"); tanto foi isto así que se fixo moito popular na Idade Media británica o seguinte proverbio, en que transparece o concepto de estrato social favorecido asociado á lingua dominante: "Jack wold be gentilman if he coude speke frensske", ou sexa, "Jack sería un cabaleiro se soubese falar francés" penetraron palabras latinas após esa conquista e reemprazaron moitos termos do inglés antigo; preto dun $85 \%$ das palabras do inglés primitivo xa non se usan. As que sobreviviron empréganse e adoito son pronomes, preposicións, conxuncións, verbos auxiliares ou palabras de carácter lexical (como mann $>$ mod. man; wif $>$ mod. wife; hus > mod. house; god > mod. good; etan > mod. eat; libban > mod. live; etc.). Notemos que xa con anterioridade o xermánico común, parte esencial do idioma inglés, adoptara moitos empréstimos do latín na época previa a que as tribos xermánicas se asentasen na Inglaterra. Outras palabras do latín derivan da influencia da Igrexa Romana despois da conversión dos ingleses ao cristianismo. Finalmente, o período que vai desde mediados do século VIII até aos comezos do XI, que se sitúa dentro do inglés antigo, é habitualmente coñecido como a Idade Viquinga e é durante este tempo que se introducen moitas palabras, antropónimos e topónimos de orixe escandinava: kid, get, bank, bull, Lincoln, Grimsby, Rugby, Whitby, Derby, Nottingham, Johnson etc.; en Baugh / Cable (2002: 98) estímase inclusivemente que o número de topónimos de orixe escandinava andaría cerca dos 600 , o que supón unha notábel cifra de toponimias desa orixe.

O Inglés Medio (1150-1500) foi un período de enormes mudanzas para a lingua como resultado da conquista normanda. Como dixemos antes, milleiros de palabras francesas e latinas penetraron no léxico e sumíronse moitas das do inglés antigo. Aínda que os normandos son de orixe danesa, isto é, xermánica, despois de invadiren a Franza nos séculos IX e X asimilaron axiña a lingua do país. A pesar de os normandos ocuparen importantes postos relixiosos, o inglés non desapareceu dos mosteiros, de forma que os relixiosos continuaron a falar as dúas linguas, aínda que moitos deles descoñecían o inglés. Outrosí, na expresión literaria tivo os seus efectos a conquista e, así, a literatura cortés e refinada e os poemas cabaleirescos estaban escritos en francés, ao paso que o inglés estaba restrinxido ás obras de carácter relixioso utilizadas para instruíren o pobo, maioritariamente de fala inglesa.

En 1204 Inglaterra perdeu Normandía. Deste modo, os normandos que ficaron na illa comezaron a paulatinamene se consideraren máis ingleses e así o inglés foise infiltrando como a lingua das clases altas. No ano 1362 fíxose oficial na xustiza

\footnotetext{
3 Proverbio tirado dunha das citacións con que comeza o traballo de Calvet (1993).
} 
e en 1385 aconteceu o mesmo nas escolas. A época comprendida entre 1348 e 1500 é habitualmente recoñecida como o período en que o inglés reemerxe como lingua dominante na propia Inglaterra e asistimos, de acordo con Willward (1996: 144-146), ao tempo do "English Triunphant". Non obstante, temos de ponderar que non había unha forma estándar culta, mais no século XV, unha das variedades, a londinense ${ }^{4}$, principiou a emerxer como o principal vehículo de expresión literaria e foi a modalidade en que escribiu Chaucer Os Contos de Canterbury ou na que Caxton, o introdutor da imprensa en Inglaterra, dá a lume as diferentes obras.

Mais o certo é que o léxico inglés tivo tamén outras proveniencias, de forma que diversas palabras chegaron á lingua a través dos procesos de conquista, contactos comerciais, colonizacións etc. Así, do novo mundo proveñen palabras cal llama, potato, barbecue, cigar etc.; do portugués incorporou menos, aínda que son máis cosmopolitas, como macaw, coconut, madeira etc.; a través do chinés penetaron voces cal mandarin ou pagoda, en canto é de orixe xaponesa a palabra bonze; do italiano chegaron palabras relacionadas co renacemento, a arte, a música e a literatura, do tipo belladonna, macaroni, casino, volcano, villa, soprano etc; outras linguas contribuiron menos, como o ruso (steppe, astrakhan etc.), o éuscaro (bizarre), o árabe (sash, fakir etc), as linguas escandinavas (rug, oaf etc.), o hindú (khaki), o turco (coffee, caviare, kiosk etc.), algunhas linguas africanas (zebra, chimpanzee etc.), ao paso que moitas foron tomadas do latín e do grego (codees, militia, specimen, arena, propaganda etc.).

Canto ao vocabulario do galego, pola súa banda, é fundamentalmente de orixe latina, aínda que ten voces de linguas preindoeuropeas (arume, carballo, morango etc.), célticas ou indoeuropeas (berro, berce, billa, tona, virar etc. $)^{5}$, xermánicas (con especial influencia na toponimia e na antroponimia: roupa, roubar, xabrón, gañar etc.; A Gudiña, Mondariz, Suevos, Castromil, Afonso, Elvira, Fernando etc.), árabes (aceite, alcohol, laranxa, xarope etc.). Así pois, as linguas dos pobos xermánicos e arábigos non deron borrado o latín galaico e en xeral a influencia do elemento xermánico na constitución do léxico galego é escasa, xa que este era un pobo guerreiro cun nivel cultural inferior aos hispano-romanos. O influxo árabe é, no entanto, algo máis relevante, aínda que ás veces non se sabe se se trata de empréstimos directos ou se chegaron a través doutras linguas románicas, como indica Ferreiro (1997: 20):

\footnotetext{
4 No inglés antigo é común falar de catro modalidades principais, como o "Northumbrian", "Mercian", "West Saxon" e "Kentish" (véxase Baugh / Cable 2002: 53). Para a situación do inglés actual, véxase o xa clásico contributo de Trudgill (1990), autor que distingue entre os "traditional dialects" e os "modern dialects".

5 Sobre a conformación do léxico galego anterior á chegada dos romanos, véxase, entre outros, Mariño (1998: 19-37) ou Rivas Quintas (1994).
} 
a invasión árabe da Península Ibérica provocou a entrada de numerosos arabismos, en xeral polos contactos fronteirizos e culturais entre árabe e galego, así como empréstimos indirectos a través do español, xa que nunca o territorio inicialmente galego estivo submetido ao dominio árabe. Mais cómpre ter en conta que o galego-portugués estivo en contacto fronteirizo co árabe desde o momento da invasión até 1250 , en que rematou a reconquista da faixa occidental da Península coa conquista do Algarve.

\section{Algunhas características fonéticas}

Xa falamos un pouco da historia externa das dúas linguas e das influencias lexicais que recibiron ao longo dos tempos. Ímonos centrar a seguir en certas dificultades de pronuncia que poden presentar algúns fonemas, problemas que veñen dados, en parte, pola propia orixe da lingua inglesa, mestura de distintas linguas (celta, latín, xermánico, francés e escandinavo), aínda que o elemento xermánico constitúe o compoñente básico orixinal. Aliás, algúns dos problemas da pronuncia son tamén debidos ao feito de a ortografía ficar sen variacións desde a época da imprensa en Inglaterra (1476), en canto que a lingua oral sufriu mudanzas profundas, nomeadamente no uso das unidades vocálicas; é certo que durante o século XIX houbo algunha tentativas de reforma ortográfica para o inglés e mesmo para o francés, mais, entre outros motivos polo peso da tradición literaria, tales revisións non foron secundadas.

Para unha persoa galegofalante que estudar inglés, o feito de o galego posuír fonemas total ou parcialmente equivalentes aos do idioma da Inglaterra pode axudala a recoñecer mellor os fonemas daquela lingua máis próximos na súa realización fonética. As seguinte reflexións están alicerzadas precisamente nesas dificultades mais tamén nesa relativa proximidade fónica. Ora, non queréndomos reparar en todos e cada un dos fonemas ingleses ${ }^{6}$, ímonos centrar naqueles que, na nosa opinión, presentaren maiores problemas para esa eventual persoa galegófona:

\subsection{Fonemas vocálicos}

1. /æ/: é anterior, entre semiaberto e aberto. É curto e non existe en galego, de modo que non equivale ao noso /a/. Está á metade de camiño entre o / $/$ / e o /a/ galegos, de forma que é máis aberto que o / $/$ / e máis fechado que o /a/. Pódese contrastar co /e/ inglés, aínda que /æ/ é máis aberto, parecéndose máis ao /a:/: bed / bad. No entanto, aínda a non existir como fonema na nosa lingua, documéntase como alofone de /a/ diante de glide ou consoante palatal (gaita ['gæjta], palla ['pæKa]) e tamén, en posicición átona, nalgunhas rexións da Galiza, como á costa occidental

6 Guiámonos aquí no elementar polo traballo de Cruttenden (1994), obra que contén, para alén da pronuncia estándar, outras variedades dialectais, cal a escocesa, a australiana ou a norteamericana. 
da provincia da Coruña (Barizo [bæ'riӨo]), o que sen dúbida, polo menos no estudantado desas zonas, podería ser considerado pedagoxicamente ${ }^{7}$.

2. / $/$ /: é un fonema semiaberto, central e curto, o que o opón ao /a/ galego, tamén central, mais máis aberto; como acontecía coa anterior, esta unidade non existe en galego. Pode contrastarse co / / inglés, aínda que este é posterior e máis aberto ${ }^{8}$ Tamén se pode contrastar co /æ/, mais este é anterior: hut (['hıt]), hot (['hot]), hat (['hæt]).

3. /ə/ (adoito denominado schwa) ${ }^{9}$ : é central, entre semiaberto e semifechado, sempre se realizando curto. É o fonema máis documentado na oralidade anglófona, xa que pode converterse nun alofone de calquera outra vogal en posición fraca ou inacentuada (Cruttenden 1994: 117). Non existe no galego común ningunha unidade vocálica comparábel ao /ə/ inglés, aínda que en certos niveis populares de lingua ou mesmo nalgunhas variedades dialectais documéntase un son [ə], de acordo co exposto en Porto Dapena (1977: 19) ${ }^{10}$ :

Se trata de un sonido intermedio entre, que sólo se deja oír a veces en pronunciación muy descuidada, equivaliendo a $o$ o $e$ ortográficas (raras veces $o$ ). Por lo demás, se encuentra fácilmente en posición inicial absoluta [...], en la terminación -es [...]. También se encuentra alguna vez en posición postónica interna, sobre todo si precede una consonante labial.

\subsection{Fonemas consonánticos}

1. /v/: en inglés, do mesmo modo noutras linguas, cal o portugués ${ }^{11}$ ou o francés, distínguese entre este fonema e o /b/, pois aquel é labiodental voceado ou sonoro e este é bilabial: [v]ote oposto a [b]oat. No galego, contrastivamente, non existe o

7 Véxase, a este respecto, Freixeiro Mato (1998: 73) ou Fernández Rei (1991: 39-40), autor, este último, que documenta o fenómeno na costa da Coruña, nas rías da Arousa, en Cambados, no galego do Courel e dos Ancares e no das Portelas, en Zamora.

8 No entanto, Cruttenden (1994: 105) fai notar que nalgunhas modalidades de inglés das Illas Británicas, como o do norte da Inglaterra ou Irlanda, non se atesta, rexistrándose no seu lugar /o/: one ['won], próximo do galego $/ \mathrm{o} /$.

9 Cfr. Catford (1994: 158), cando di que este fonema, "traditionally known as schwa, which is the German spelling of the name of a Hebrew letter representing a vowel of this type, is used for any midcentral vowel, i. e., a vowel of the central type between half-close and half-open".

10 Tamén se documenta en portugués, adoito cando nos achamos graficamente diante dun $<e>$ átono. Cfr., sobre este particular, Martins (1998: 85, 90, 128).

${ }^{11}$ Convén notarmos que o fonema labiodental voceado só existe no centro e sur do país, pois nos falares do norte, en xeral máis conservadores e máis próximos do galego, non se atesta. Véxase neste sentido Cintra (1995: 95-105). 
fonema labiodental voceado /v/, o que leva producido non poucas dificultades para o alumnado que está a aprender esa llingua.

2. $\mathrm{O} / \mathrm{t} / \mathrm{e} \mathrm{o} / \mathrm{d} / \mathrm{s}$ son alveolares, en canto en galego son dentais. Esta diferenza si que se manifesta cando se falar inglés e non se corrixir isto e, así mesmo, tende a causar certa graza escoitarmos falar utentes de linguas xermánicas expresándose en galego pronunciando o /t/ e o /d/ alveolares. Crunttenden (1994: 151), porén, salienta que nalgunhas rexións anglófonas non se detecta o mesmo grao de aspiración característica da variedade estándar, como na Escocia, Gales ou na Irlanda.

3. A consoante / / é fricativa, interdental, voceada. É máis fraca e curta que o fonema $/ \theta /$, que é moi semellante ao $/ \theta /$ galego da palabra zapato ([Өa'pato]). Porén, temos de destacar que hai rexións do noso país en que non existe este fonema interdental, ou sexa, nas áreas en que se dá o fenómeno do seseo ${ }^{12}$. Esta particularidade dialectal, isto é, a ausencia da interdental, coincide coa do inglés en palabras que se escriben con $\langle c\rangle,\langle s\rangle$ ou $\langle s s\rangle$ : cecil, soap, passing. En galego o fonema $/ / /$ non existe como tal, mais dáse como alofone aproximante da oclusiva dental voceada /d/, comunmente en posición medial (amado [a'mað̦o]) ou, en xeral, rodeado ou en contacto con fonemas voceados (arder [ar'ơer]).

4. O /z/ inglés é fricativo, alveolar, voceado. Esta última característica é a que a distingue do /s/, aparte de que é máis feble e curto. No galego común o /z/ non existe como fonema, a pesar de, minoritariamente, se atestar nalgunhas áreas do país ${ }^{13}$. O estudante galego debe distinguilo do /s/, xa que hai distinción fonolóxica entre ámbolos dous: zeal, seal.

5. O fonema / $/$ inglés é fricativo, palato-alveolar, non voceado e non presenta dificultades para o estudante galego, xa que pola súa notábel proximidade co / $/$ do noso idioma. Con todo, existen rexións en que esta consoante palatal sufriu un proceso de despalatalización, como algunhas zonas costeiras, o que talvez poida resultar algo problemático para o alumnado proveniente desas comarcas cando tiver de aprender a pronuncia deste fonema inglés.

6. A consoante /3/ é fricativa, palato-alveolar, voceada. Á diferenza do anterior, é voceado e fraco. Como non existe ningún fonema semellante no galego común, aínda que si dialectalmente ${ }^{14}$, hai que o aprender repetíndoo en voz alta e ouvíndoo moitas veces.

12 A respecto da ausencia da consoante interdental fricativa xorda na lingua galega actual canto a extensión xeográfica, orixes, valoración social, tipoloxías de seseo véxase Fernández Rei (1991: 189-215) ou Freixeiro Mato (1998: 162-175).

13 Véxase Fernández Rei (1991: 210-213) ou Freixeiro Mato (1998: 166-169).

${ }^{14}$ Di Fernández Rei (1991: 56): "No suroeste de Ourense, no concello de Crespos-Padrenda e en especial nos de Entrimo e Lobios, así coma no zamorano de Hermisende existe un sistema de seis sibilan- 
7. O /r/ inglés é fricativo, posalveolar, voceado. É a realización máis usual do $r$ inglés e, alén diso, é o único posíbel en posición inicial: red. Por outro lado, existe tamén unha consoante / / / vibrante, alveolar, voceada, semellante ao / $/$ / simple do noso idioma. A situación do galego non coincide, pois, coa inglesa: existe un fonema vibrante simple alveolar, voceado / / / (caro ['karo]) e o vibrante múltiple /r/ (carro ['karo]); en inglés, en confronto, só existe un fonema /r/ que se pronuncia o mesmo tanto se se escribe $<r>$ como $<r r>$, polo que o estudante galego debe aprender a facer esa distinción.

8. O fonema /h/ é fricativo, glotal, xordo e prodúcese por medio dunha aspiración e mesmo pode chegar a ser mudo se esta non se producir. A ausencia da pronuncia do /h/ é un signo de incultura, á parte de que tamén conleva unha diferenza fonolóxica. É menor o erro de pronunciar o /h/ demasiado forte, aínda que de todos os xeitos isto soa moi desagradábel aos ouvidos ingleses; isto é característico das persoas galegofalantes, confundindo o fonema /h/ inglés co /x/ español. Así, débese procurar, ao pronunciar o $/ \mathrm{h} /$ inglés aspirado, efectuar o contacto coa glote. No entanto, en galego dáse unha pronuncia [h] nas áreas de gheada, isto é, nas rexións occidentais do país, co que nos achamos diante dun outro punto fonético en común entre os dous idiomas.

9. En inglés, /dz/ é unha consoante africada, palato-alveolar, voceada, que non existe no galego. A diferenza deste fonema con respecto ao / $\mathrm{t} \int$ / consiste en que é voceado, para alen de que a fricción é máis fraca e curta que para $/ \mathrm{t} \int /$.

10. Finalmente, a consoante $/ \mathrm{y} /$ inglesa é moi semellante ao noso / $\mathrm{y} /$, tamén nasal, velar e voceado, como na palabra unha (['ũ̃ã]) ou como, en xeral, en posición final absoluta (corazón [kora'Өõn]. Doutro lado, na nosa lingua, como tamén noutras do ámbito románico, existe o fonema /n/ nasal, palatal, voceado, que non se rexistra en inglés.

\section{Conclusións}

A nosa intención nas páxinas precedentes foi, por un lado, facermos unha apresurada viaxe pola historia externa do inglés e pórmola en comparación coa do galego, e, por outro lado, pretendeuse incidir nalgunhas diferenzas e similitudes fonéticas entre ambas as linguas. De se levar ás aulas do ensino preuniversitario unha aproximación similar a esta, coidamos que o estudantado resultaría beneficiado tamén dun modo duplo: en primeiro lugar, descubriría que a lingua máis influente

tes, semellante ó existente na zona portuguesa de Trás-os-Montes próxima a Galicia e mais no noroeste da rexión miñota do país veciño". A primeira parella que distingue este estudioso é, precisamente, a dos fonemas prepalatais fricativos, o non voceado / $/$ (caixa ['kæj $\left.\int a\right]$ ) e o voceado /3/ (gente ['zẽnte], queijo ['kej3o] 
na actualidade se achaba, na Idade Media, nunha situación parecida á do galego dos nosos días e que deu mudado a súa historia, recuperando os usos de que fora desposuída, na mesma liña do que aspiramos tamén para o noso idioma; e en segundo lugar, sendo certo que existen notábeis diferenzas fonéticas entre o inglés e o galego, hai, asemade, algunha relativa proximidade entre os fonemas de ambos, o que sen dúbida pode e debe ser aproveitado nas aulas, sempre na procura dunha relacion docencia-discencia o máis académica, rigorosa e pedagóxica posíbel.

\section{Referencias bibliográficas}

Baugh, A. B. / Cable, T. (2002) [1951]: A history of the English language (London: Routledge).

Calvet, L.-J. (1993): Lingüística e colonialismo. Pequeno tratado de glotofaxia (Santiago de Compostela: Laiovento).

Catford, J. C. (1994) [1988]: A Practical Introduction to Phonetiks (Oxford: Clarendon Press).

Cintra, L. F. Lindley (1995): Estudos de Dialectologia Portuguesa (Lisboa: Sá da Costa).

Crutteden, A. (1994): Gimson's Pronunciation of English (London / New York / Melbourne / Aukland: Edward Arnold).

Fernández Rei, F. (1991) [1990]: Dialectoloxía da lingua galega (Vigo: Xerais).

Ferreiro, M. (1997): Gramática histórica galega. Vol. II. Lexicoloxía (Santiago de Compostela: Laiovento).

Freixeiro Mato, X. R. (1998): Gramática da lingua galega. Vol. I. Fonética e Fonoloxía (Vigo: A Nosa Terra).

Hogg, R. (2002): An Introduction to Old English (Edinburgh: Edinburgh University Press).

Hubert, H. (1988): Los celtas y la civilización céltica (Madrid: Akal).

Mariño Paz, R. (1998): Historia da lingua galega (Santiago de Compostela: Sotelo Blanco).

Martins, M. R. Delgado (1998) [1988]: Ouvir Falar. Introdução à Fonética do Português (Lisboa: Caminho).

Millward, C. M. (1996) [1988]: A Biography of the English Language (Florida: Holt, Rinehart \& Winston(. 
Porto Dapena, J. A. (1977): El gallego hablado en la comarca ferrolana. Anexo 9 de Verba (Santiago de Compostela: Universidade de Santiago de Compostela).

Powell, T. (2000) [1958]: The Celts (London: Thames \& Hudson).

Rivas Quintas, E. (1994): Lingua galega: nivéis primitivos (Santiago de Compostela: Laiovento).

Trudgill, P. (1990): The Dialects of England (Cambridge-Massachusetts / Oxford: Basil Blackwell). 